\title{
Identification and manipulation of Neurospora crassa genes involved in sensitivity to furfural
}

Daria Feldman ${ }^{1 \dagger}$, David J. Kowbel ${ }^{2 \dagger}$, Adi Cohen ${ }^{1}$, N. Louise Glass ${ }^{2,3}$, Yitzhak Hadar $^{1}$ and Oded Yarden ${ }^{1 *}(\mathbb{C}$

\begin{abstract}
Background: Biofuels derived from lignocellulosic biomass are a viable alternative to fossil fuels required for transportation. Following plant biomass pretreatment, the furan derivative furfural is present at concentrations which are inhibitory to yeasts. Detoxification of furfural is thus important for efficient fermentation. Here, we searched for new genetic attributes in the fungus Neurospora crassa that may be linked to furfural tolerance. The fact that furfural is involved in the natural process of sexual spore germination of $\mathrm{N}$. crassa and that this fungus is highly amenable to genetic manipulations makes it a rational candidate for this study.

Results: Both hypothesis-based and unbiased (random promotor mutagenesis) approaches were performed to identify N. crassa genes associated with the response to furfural. Changes in the transcriptional profile following exposure to furfural revealed that the affected processes were, overall, similar to those observed in Saccharomyces cerevisiae. N. crassa was more tolerant (by $~ 30 \%$ ) to furfural when carboxymethyl cellulose was the main carbon source as opposed to sucrose, indicative of a link between carbohydrate metabolism and furfural tolerance. We also observed increased tolerance in a $\triangle c r e-1$ mutant (CRE-1 is a key transcription factor that regulates the ability of fungi to utilize non-preferred carbon sources). In addition, analysis of aldehyde dehydrogenase mutants showed that ahd-2 (NCU00378) was involved in tolerance to furfural as well as the predicted membrane transporter NCU05580 (fr-1), a homolog of FLR1 in S. cerevisiae. Further to the rational screening, an unbiased approach revealed additional genes whose inactivation conferred increased tolerance to furfural: (i) NCU02488, which affected the abundance of the nonanchored cell wall protein NCW-1 (NCU05137), and (ii) the zinc finger protein NCU01407.

Conclusions: We identified attributes in N. crassa associated with tolerance or degradation of furfural, using complementary research approaches. The manipulation of the genes involved in furan sensitivity can provide a means for improving the production of biofuel producing strains. Similar research approaches can be utilized in N. crassa and other filamentous fungi to identify additional attributes relevant to other furans or toxic chemicals.
\end{abstract}

Keywords: Furfural, Neurospora crassa, Furan, Pretreatment, CRE1, Aldehyde dehydrogenases

\footnotetext{
*Correspondence: oded.yarden@mail.huji.ac.il

${ }^{\dagger}$ Daria Feldman and David J. Kowbel contributed equally to this work

${ }^{1}$ Department of Plant Pathology and Microbiology, The R.H. Smith Faculty Agriculture, Food and Environment, The Hebrew University of Jerusalem, 7600001 Rehovot, Israel

Full list of author information is available at the end of the article
} 


\section{Introduction}

Biofuels derived from lignocellulosic biomass are a viable alternative to fossil fuels required for transportation [1]. In second-generation biofuels, pretreatment of plant biomass using a thermo and/or chemical process is necessary to make carbohydrates available for enzymatic hydrolysis and fermentation by disrupting their linkage to lignin in the plant cell wall [1,2]. The beneficial effects of pretreatment of lignocellulosic materials have been recognized for a long time, and the goal of the process is to remove lignin, reduce the crystallinity of cellulose, and increase the porosity of the lignocellulosic materials $[1,3$, 4].

The pretreatment processes, using dilute acid and wet oxidation, are accompanied by the production of inhibitory compounds, particularly furans, that can inhibit efficient sugar utilization by fermentation organisms, mainly Saccharomyces cerevisiae [3,5-7], thus imposing a ratelimiting step in production. Two of the furan derivatives generated during these pretreatment are 5-hydroxymethyl-2-furaldehyde (HMF) and furfural, which are the most potent microbial inhibitors that are formed by dehydration of hexoses and pentoses, respectively [8-11]. The quantities of furans produced vary based on the type of raw material used and the pretreatment procedure employed. Furfural is usually found at lower levels than HMF. However, it is often present at a sufficient concentration $(\sim 1 \mathrm{~g} / \mathrm{l})$ to be inhibitory $[3,12,13]$.

Furfural has been studied intensively and its conversion to furfuryl alcohol (furan methanol) and further reduction to 2 -furoic acid by $S$. cerevisiae has been demonstrated $[14,15]$. After exposure to furfural, S. cerevisiae proteins involved in glucose fermentation and the tricarboxylic acid cycle were found to be more abundant in the exposed cells than in the untreated controls, while the abundance of proteins involved in glycerol biosynthesis were reduced. The aldehyde dehydrogenases Adh5p and Adh1p were suggested to be the catalytic agents for furfural reduction [16]. ${ }^{13} \mathrm{C}$-labeled metabolic flux and transcriptional analyses showed that ADH7 and YKL071W (NADH-dependent aldehyde reductase) are associated with yeast resistance to furfural [17]. Another important element in mediating yeast tolerance is the pleiotropic drug resistance (PDR) family, which function as ATP binding and chemical resistance agents. Genes encoding PDRs display a consistent increase in expression when S. cerevisiae is exposed by furfural and HMF, promoting cellular survival and adaptation to the inhibitor-induced stress [18-20].

Research on the filamentous fungus Neurospora crassa benefits from a large toolbox of molecular, genomics, and cytological techniques that are unavailable for most other filamentous fungi [21-23]. These assets include a near-full genome deletion strain set of $\sim 12,500$ mutants [24]. In nature, N. crassa grows on the stems of grasses, e.g., sugarcane that has been recently killed by burning [25-28]. In recent years, the ability of $N$. crassa to grow on plant material became the focus of studies that revealed that under such conditions the expression and secretion of a large number of cellulases, hemicellulases and proteins of unknown function are induced [29]. Thus, $N$. crassa has also become an important organism relevant to understanding plant cell wall degradation by fungi and, subsequently, elucidating some of the potential mechanisms that can be exploited for increasing biofuel yield [30-34]. It was also shown that furfural, produced during burning of plant substrates, can function as an inducer of sexual spore germination in $N$. crassa $[25,35$, 36]. In addition, a decrease in concentrations of furfural occurred during fermentation of plant biomass by $N$. crassa [37]. These studies suggest that $N$. crassa can cope with furfural by the expression of unique genes or pathways that, once identified, can be potentially exploited by expression in a heterologous manner in fermentation organisms.

The aim of this study was to uncover new genetic attributes in $N$. crassa involved in conferring tolerance to furfural, using complementing experimental approaches. Based on RNA-seq data analyses, an aldehyde dehydrogenase ahd-2 (NCU00378) and the transcription factor responsible for carbon catabolite repression, cre-1, were identified to be involved in tolerance to furfural. Using a hypothesis-driven approach and based on screening relevant known homologs from other organisms, a predicted membrane transporter (NCU05580) was identified as relevant to furfural sensitivity. Lastly, using an unbiased approach, in which a tagged promotor cassette was randomly integrated into the fungal genome, we determined that inactivation of two hypothetical proteins, NCU02488 or NCU01407, resulted in increased tolerance of $N$. crassa to furfural.

\section{Results \\ Developmental and physiological responses of $N$. crassa to furfural \\ The effect of furfural on growth rate}

The toxic effect of different furfural concentrations on the relative growth rate of $N$. crassa was measured. Furfural affected conidial germination and subsequent colony development in a dose-dependent manner with an $\mathrm{IC}_{50} \sim 12.5 \mathrm{mM}$, as measured $20 \mathrm{~h}$ post inoculation (Additional file 1: Figure S1A). The inhibitory value we measured was similar to the $\mathrm{IC}_{50}$ of $16 \mathrm{mM}$ measured for S. cerevisiae [38].

To further monitor the effect of furfural on colony growth, we used a high throughput 96-well plate system. 
Liquid medium was inoculated with conidia of $N$. crassa and supplemented with different concentrations of furfural (15-75 mM) (Fig. 1a). Two main parameters were measured to assess the inhibitory effects: (i) the lag phase, referring to the time required for initiation of culture biomass accumulation as compared to the control lacking furfural, and (ii) the inhibition in relative growth rate, as determined by measuring the O.D. of cultures exposed to furfural compared to that of the control $20 \mathrm{~h}$ after inoculation. We focused on the 15, 30 and $60 \mathrm{mM}$ furfural treatments, which imposed a lag period in colony development of $0.96,2.16$ and $4.77 \mathrm{~h}$, as compared to untreated controls (Fig. 1b). Growth inhibition (as determined at the $20 \mathrm{~h}$ time point) also correlated to the furfural concentration, resulting in 12, 25 and $57 \%$, at the respective furfural concentrations (Fig. 1c).

\section{Furfural inhibits conidial germination}

We hypothesized that the extended lag phase in the 96-well screen was due to a delay in conidial germination. To address this possibility, $N$. crassa conidia were inoculated into medium amended with a high dose of furfural $(60 \mathrm{mM})$. The growth of the fungus was completely inhibited during the first $40 \mathrm{~h}$, after which it recovered and the growth was inhibited by only $\sim 36 \%$ (natural degradation of furfural was negligible) (Additional file 1: Figure S1B), supporting the occurrence of increased toxicity during germination. This result led us to further explore
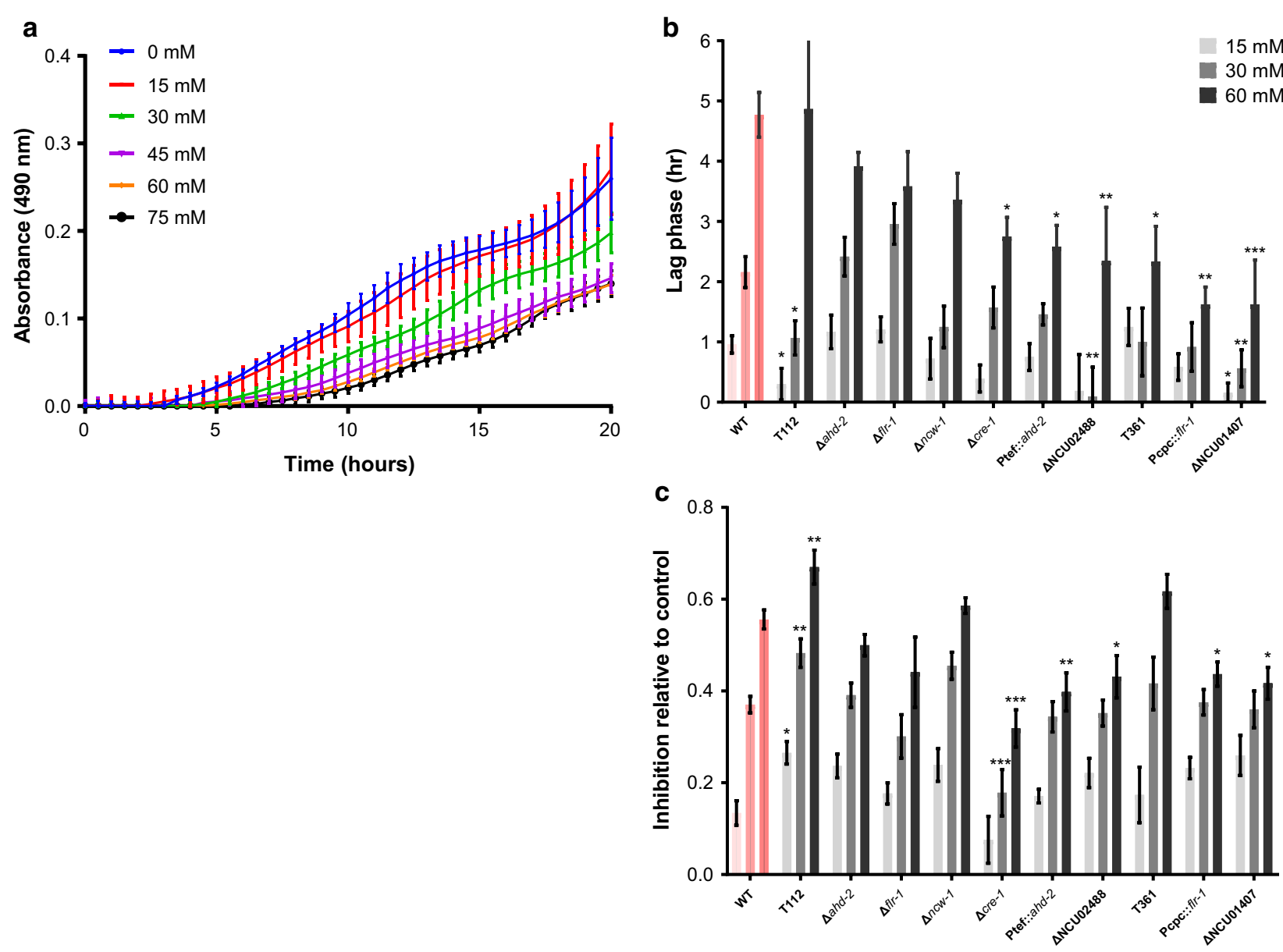

Strains

Fig. 1 Effect of furfural on growth of N. crassa wild-type and mutant strains in a 96-well plate assay, as measured at $490 \mathrm{~nm}$. a Wells of a 96-well plate were inoculated with $4 \times 10^{5}$ conidia of the wild-type strain in VgS media supplemented with different concentrations (15-75 mM) of furfural. b Delay in lag phase as expressed in the time required for detectable initiation of culture growth, compared to the control lacking furfural (15, 30 and $60 \mathrm{mM}$ ). c Inhibition in relative growth, as determined by O.D. of cultures exposed to furfural $(15,30$ and $60 \mathrm{mM})$ relative to that of the control, $20 \mathrm{~h}$ after inoculation. Asterisks in $\mathbf{b}, \mathbf{c}$ indicate a significant difference between the mutant strains and wild-type subjected to the same treatment $\left({ }^{*} P<0.05,{ }^{* *} P<0.01\right.$, and ${ }^{* *} P<0.001$ by Student's $t$ test). The wild-type control is shown in pink. The values represent the average of at least six biological replicates 
the effect of the compound on conidial germination. We monitored the germination rate of conidia 4 and $6 \mathrm{~h}$ after inoculation, after which $\sim 75 \%$ and $\sim 90 \%$ of the control conidia germinated at these two time points, while only $12 \%$ and $47 \%$ of the conidia exposed to $30 \mathrm{mM}$ furfural did so (Fig. 2). These data suggest that the major effect of furfural was in delaying asexual spore germination.

\section{Furfural is similarly reduced by either NADH or NADPH}

In $S$. cerevisiae, intracellular furfural is reduced within the intracellular fraction by either NADPH or NADH as co-factors $[14,20,39]$. When we monitored the ability of $N$. crassa cell-free extracts to reduce furfural in vitro, and specific activity as measured by $\mathrm{NAD}(\mathrm{P}) \mathrm{H}$ depletion, we found a similar effect with both co-factors (Fig. 3a). These results suggest that the intracellular enzymes involved in the reduction were not specific and included those that can utilize either NADH or NADPH. Thus, it is possible that several different cellular pathways may be involved in modification of furfural.

Changes in gene expression following exposure to furfural RNA-seq was performed to assess the genetic response of $N$. crassa to furfural and to identify potential targets

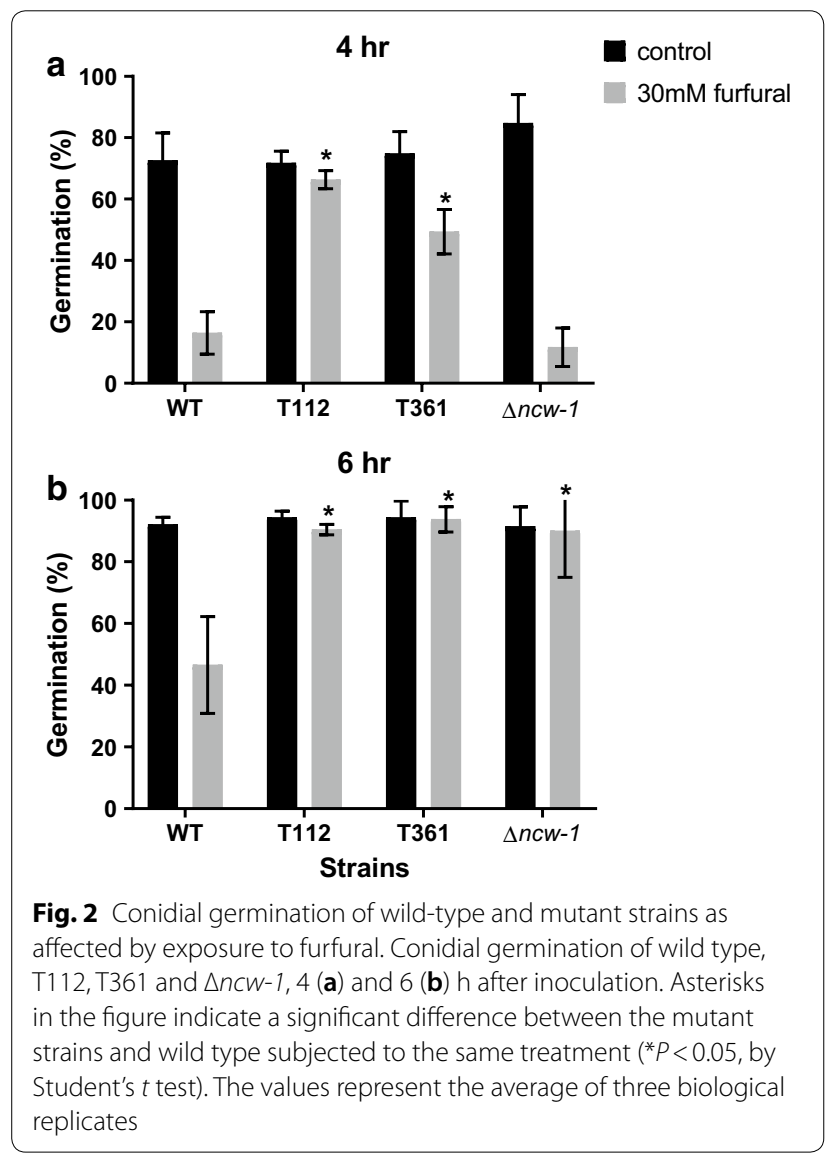

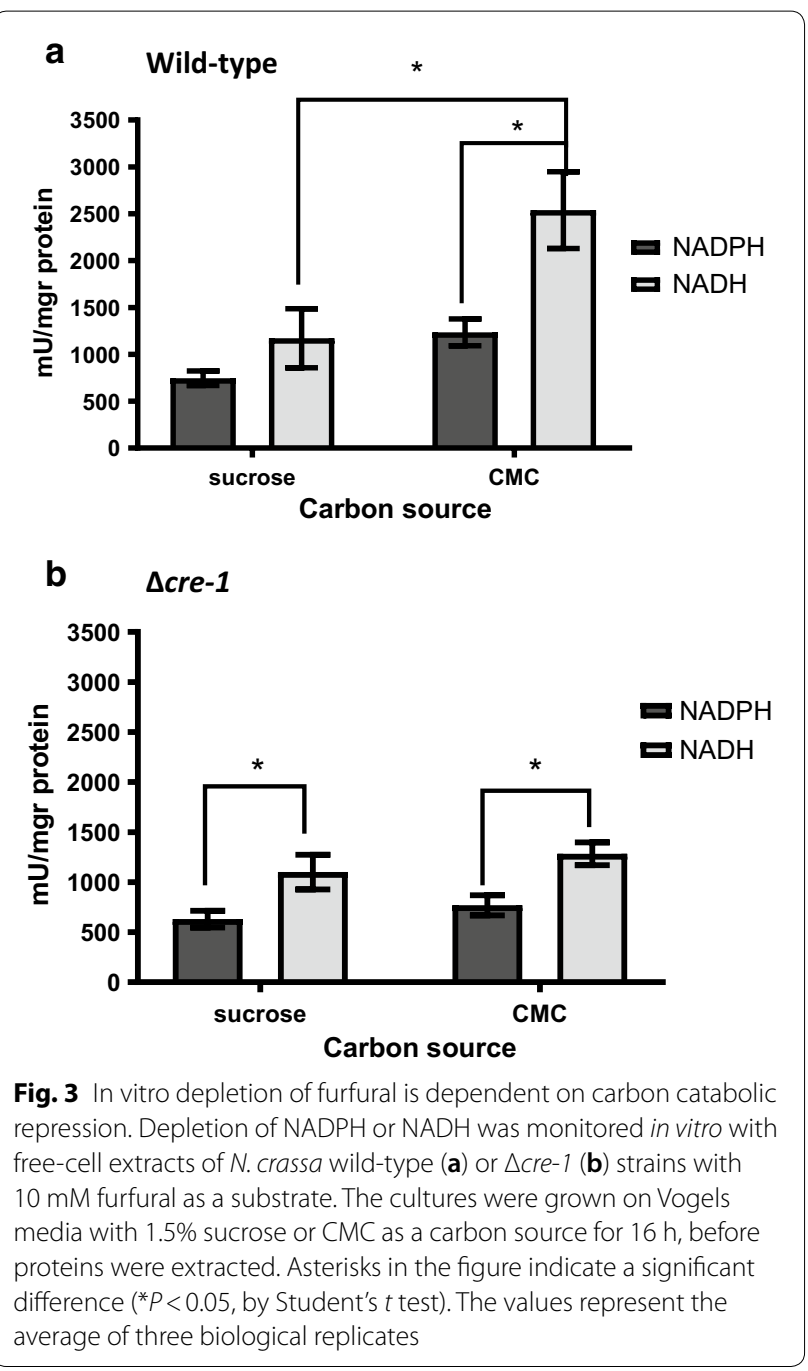

for subsequent gene manipulation experiments. N. crassa was exposed to $10 \mathrm{mM}$ furfural for $4 \mathrm{~h}$, to achieve $35 \%$ inhibition in biomass accumulation as compared to the control. Total RNA isolated and used to construct RNAseq libraries was analyzed using hierarchical clustering (Fig. 4a) and clustered by Euclidean distance (Fig. 4c). The overall summary of the RNA-seq analysis is shown in Additional file 2: Table S1. Following exposure to furfural, an increase in the expression levels of 385 genes was observed, while that of 551 genes was reduced (Fig. 4b). Parallel to the analysis of the transcriptional response to the presence of furfural, we also performed RNA-seq analyses of cultures exposed to HMF, another inhibitory furan produced during pre-treatment with dilute acid or wet oxidation. Exposure to $10 \mathrm{mM}$ of HMF was accompanied by increased differential expression of 125 genes, and a reduction in that of 146 genes (Fig. 4b).

Biological processes affected by exposure to furfural $(P$ value $<0.01)$ included: translation, transcription, 


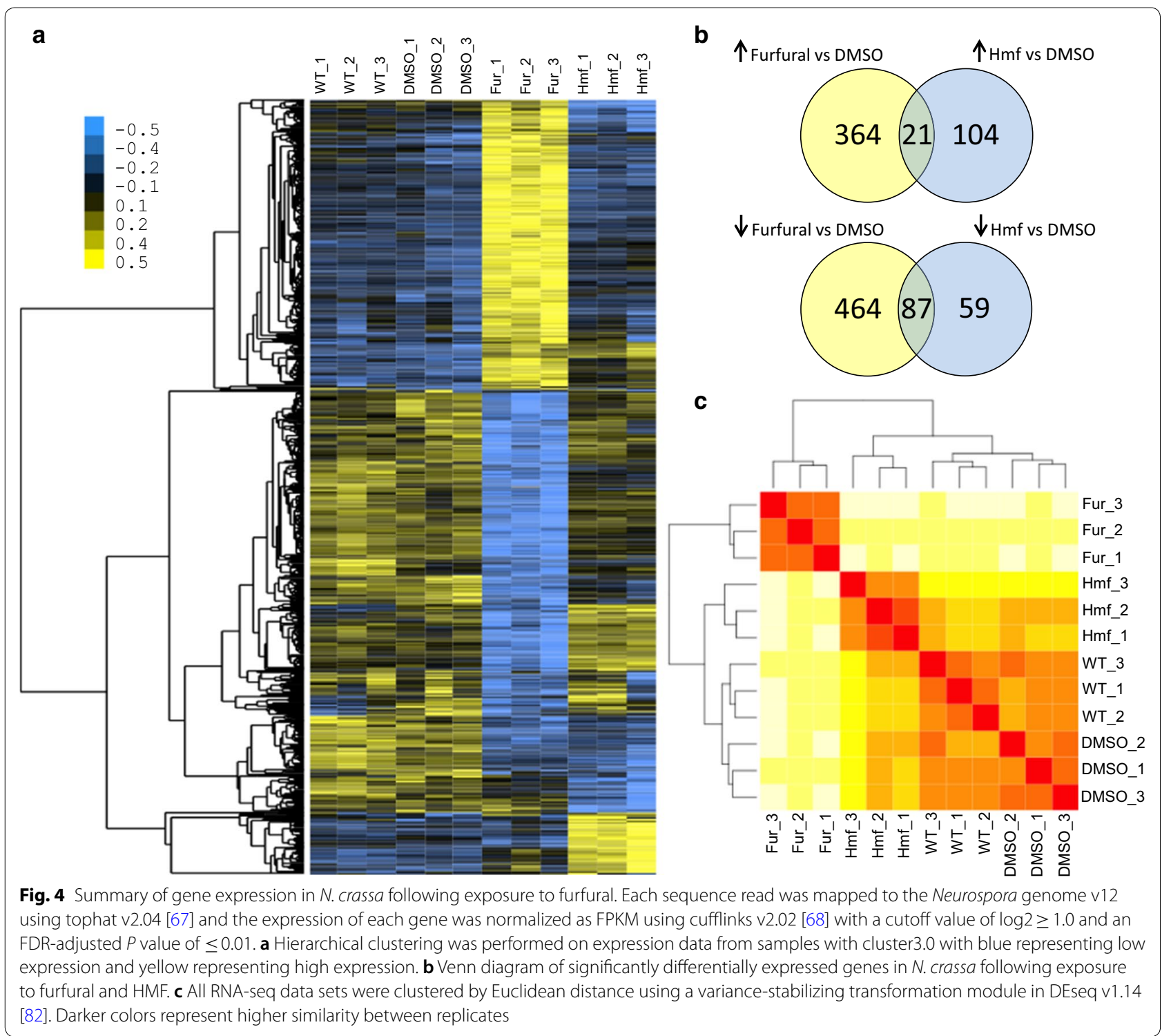

transmembrane transport, alpha-amino acid biosynthesis, oxidation-reduction processes, mitochondrial organization, carbohydrate metabolic processes, transport, and cellular amino acid metabolic processes. Notable genes whose expression levels were increased following exposure to furfural included alternative oxidase 1 (NCU07953) and genes encoding enzymes in branchedchain amino acid synthesis (NCU09864, NCU03913 and NCU02704 (Additional file 1: Table S2).

The largest child GO term associated with genes that showed increased expression levels upon exposure to furfural was "oxidation-reduction process" (GO:0055114) with 53 genes. The genes with at least a fourfold increase in FPKM (fragments per kilobase of unique exons per million mapped reads in library) encode a predicted trichothecene C-15 hydroxylase (NCU00732), an alternative oxidase-1 (NCU07953), a pentachlorophenol monooxygenase (NCU04591), a phosphoenolpyruvate carboxykinase (NCU09873), a homogentisate 1,2-dioxygenase (NCU05499), a monooxygenase (NCU08747), a 4-hydroxyphenylpyruvate dioxygenase (NCU01830), hypothetical proteins (NCU02031 and NCU09165), an $\mathrm{NADPH}$-adrenodoxin reductase (NCU08005), a malate synthase (NCU10007), a cytochrome B5 (NCU08060), and a isovaleryl-CoA dehydrogenase (NCU02126) (Additional file 3: Table S9).

A one-tailed Fisher's exact test was used to assess which GO terms were significantly enriched by exposure to furfural (Fig. 5 and Additional file 3: Table S9). A number of processes associated with amino acid metabolism 


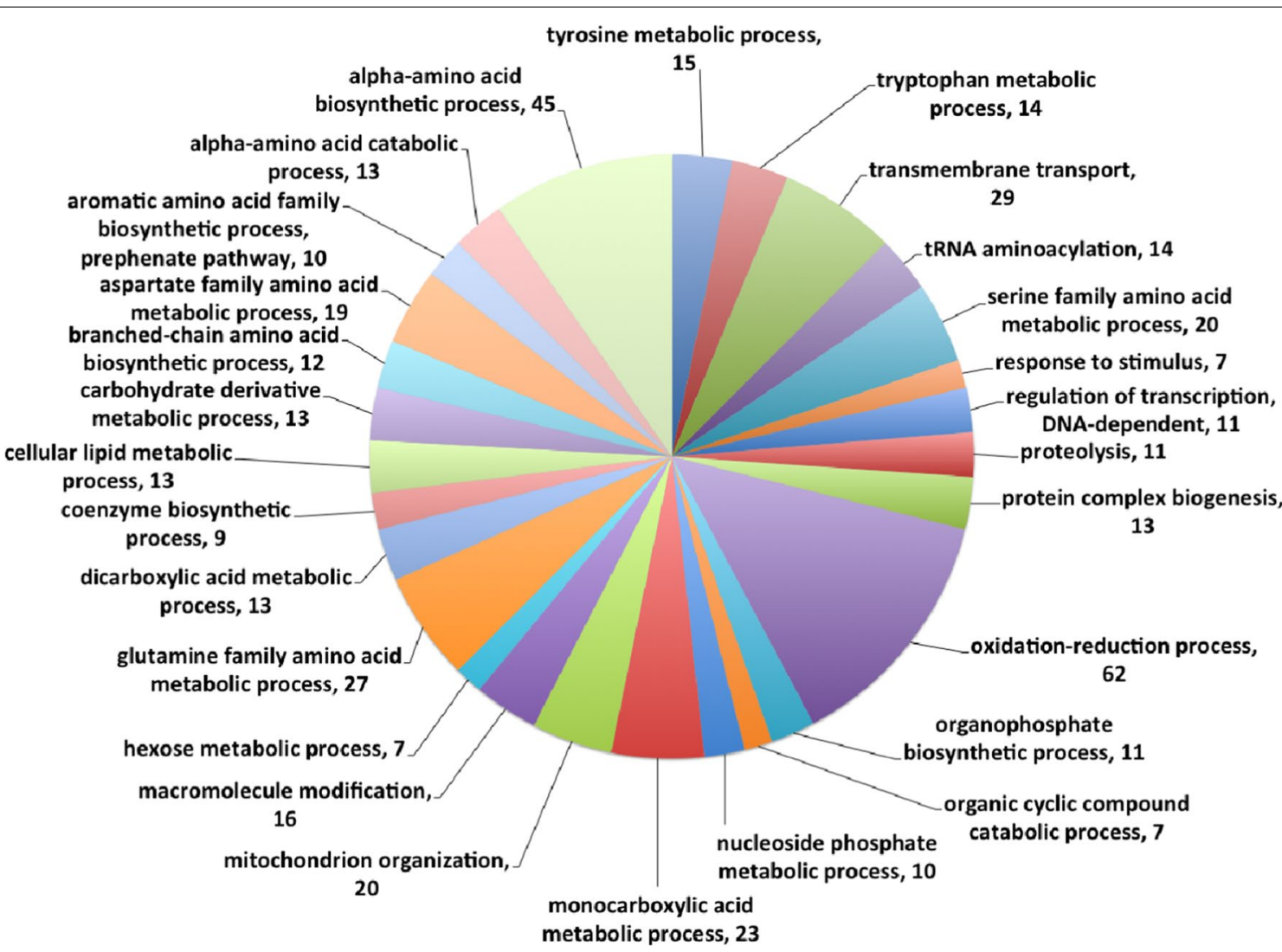

Fig. 5 GO terms associated with biological processes affected upon exposure to furfural in N. crassa. GO terms were associated with all protein coding genes using the program Blast2Go v 2.8 [70] and a multilevel pie chart generated from genes that are up regulated with a log 2 value $\geq 1.0$ and $P$-adjusted value $\leq 0.01$ and a node score $>6.0$. Only terminal nodes are presented in the pie chart with the node score for each biological process

showed significant enrichment, including "alpha-amino acid metabolism" (adjusted $P$ value $5.9 \mathrm{e}-13$ ), "aspartate family amino acid metabolism" (adjusted $P$ value $4.1 \mathrm{e}-4$ ) and "glutamine family amino acid metabolism" (adjusted $P$ value $3.3 \mathrm{e}-4)$. In addition, "tRNA aminoacylation", which is necessary for t-RNA ligation to its specific amino acid during translation, was enriched (adjusted $P$ value $7.1 \mathrm{e}-7$ ). Exposure to furfural significantly affected the expression of genes in the aspartate family, including isoleucine, threonine, lysine, methionine and asparagine and the glutamine family, and proline and glutamate amino acid biosynthesis pathways. The GO term for "oxidation-reduction processes" was also significantly enriched (adjusted $P$ value $4.6 \mathrm{e}-4$ ).

Genes that showed a significant decrease in expression upon exposure to furfural included structural ribosomal constituents (adjusted $P$ value 7.2e5) and all encoded ribosomal proteins. Forty-three genes associated with "carbohydrate metabolic processes" (adjusted $P$ value 7.2e-5) also showed significant downregulation by exposure to furfural. Three genes that showed significant downregulation (at least fourfold) included ncw-1 (NCU05137), encoding a non-anchored cell wall protein [40] and 1,3-beta-glucanosyltransferase genes (NCU07253 and NCU08909), which encode predicted cell wall proteins in N. crassa [41].

We screened 13 deletion mutants of genes that had the highest up- or downregulation in response to furfural from the Neurospora deletion collection, which were obtained from the FGSC (Fungal Genetics Stock Center) [42]. Seven mutants contained a deletion of genes that were upregulated in response to furfural (NCU04697, NCU00732, NCU07953, NCU04591, NCU05045, NCU08561 and NCU08096), and five mutants containing a deletion of genes that were downregulated in response to furfural (NCU08907, NCU08720, NCU08457, NCU06912 and NCU00399). Six additional mutants, each containing a deletion of one of six genes that were significantly affected by the presence of HMF, were also screened for sensitivity to HMF. All the deletion strains exhibited a similar tolerance to either furfural or HMF as the wild-type parental strain (Additional file 1: Table S3). 
Overall, while RNA-seq has provided a metabolic overview of the fungal transcriptome in response to the presence of furfural, the functional contribution of genes was not apparent by a standard single-gene reverse genetics approach.

\section{Attributes of furfural tolerance identified by RNA-seq analyses \\ Carbohydrate metabolic processes and catabolic repression involved in tolerance toward furfural}

The RNA-seq data in response of $N$. crassa to furfural showed that "carbohydrate metabolic process" was the most significantly downregulated biological process GO term (GO:0005975, $P$ value: 7.2e-5). To delineate the possible link between furfural and carbohydrate metabolism, we characterized the sensitivity of $N$. crassa to furfural in the presence of different carbon sources. When the media contained xylose or glycerol instead of sucrose, wild-type cells were significantly more tolerant (by approximately 15\%) to $15 \mathrm{mM}$ furfural. Tolerance was even more pronounced (about 30\%) when N. crassa was cultured on carboxymethyl cellulose (CMC). When sucrose was replaced with other fermentable sugars such as glucose or fructose, no change in sensitivity to furfural was observed (inhibition with sucrose was $57 \%$ relative to control, glucose and fructose presented similar inhibition with difference in values of up to $5 \%$ of the standard error).

To understand if the effect of non-fermentable sugars in vivo might be related to furfural degradation within the intracellular fraction, we compared the ability of $N$. crassa cell extracts to reduce furfural. We monitored $\mathrm{NAD}(\mathrm{P}) \mathrm{H}$ depletion in cell-free extracts obtained from cultures grown overnight on either sucrose or CMC, with furfural as the substrate. The activity measured with both co-factors increased significantly when cultures were grown on CMC as compared to sucrose (by $215 \%$ for NADH and $165 \%$ for NADPH) (Fig. 3a). In contrast to cultures grown on sucrose, on CMC, the specific activity coupled with NADH was significantly higher than with NADPH (2540 and $1235 \mathrm{mU} / \mathrm{mg}$ protein, respectively). These results suggest that the increased tolerance of $N$. crassa to furfural in vivo may be due, to a major extent, to the elevation in the amount or activity of enzymes that can reduce furfural using NADH as a co-factor.

In filamentous ascomycete fungi, the utilization of alternate carbon sources is partially controlled by the zinc finger transcription factor CreA/CRE-1, which is a carbon catabolite repressor (CCR) protein [30, 34, 43-47]. Since our results suggested that non-fermentable sugars affected sensitivity to furfural in vivo and in vitro, we analyzed the ability of a cre-1 deletion strain to grow on media containing sucrose supplemented with furfural. When grown on sucrose, $\Delta c r e-1$ de-represses many genes, which mimics the behavior of wild-type on non-fermentable sugars [47]. Under these conditions, we found that $\Delta c r e-1$ is $30 \%$ more tolerant to $15 \mathrm{mM}$ of furfural in solid media, relative to wild-type cells. In a 96-well plate assay, the $\Delta c r e-1$ mutant also exhibited a significantly shorter lag phase of $2.75 \mathrm{~h}$ following exposure to $60 \mathrm{mM}$ furfural (a reduction of $2 \mathrm{~h}$ relative to the wild-type strain). The $\Delta c r e-1$ mutant was also significantly more tolerant to 30 and $60 \mathrm{mM}$ concentrations of the furan (30 and $51 \%$, respectively) (Fig. 1). When $\mathrm{CMC}$, known to suppress the growth arrest of the $\Delta$ cre1 mutant [47], was used as a sole carbon source, no significant difference in growth was evident as compared to the wild-type strain at $15 \mathrm{mM}$ of furfural. These data suggest that CCR affects resistance to furfural in vivo and that this effect is mediated through CRE-1 regulatory pathways.

\section{The ahd-2 (NCU00378) gene is involved in tolerance toward furfural}

In $S$. cerevisiae, furfural is detoxified by aldehyde dehydrogenases [39]. We, therefore, examined expression profiles for genes encoding predicted aldehyde dehydrogenases from our furfural RNA-seq dataset for those that displayed changes in their transcriptional pattern, and were either up- or downregulated when exposed to furfural. Five putative aldehyde dehydrogenase genes met these criteria: NCU03076, NCU03415, NCU09648, NCU00936 and NCU00378. The phenotypic consequences of exposing strains carrying a deletion of each of these predicted aldehyde dehydrogenase genes to $60 \mathrm{mM}$ furfural were assessed: one mutant, $\triangle \mathrm{NCU00378,}$ previously designated aldehyde dehydrogenase-2 (ahd2) [48], was $43 \%$ more sensitive to $60 \mathrm{mM}$ furfural than the wild type on solid media (Additional file 1: Table S5). This sensitivity of the $\Delta a h d-2$ mutant was observed only when cultured on solid medium. This strain did not exhibit an increase in the lag phase or inhibition of growth in 96-well plate assays (Fig. 1). ahd-2 was previously reported to be involved in indole-3-pyruvic acid pathway-mediated biosynthesis of auxin in N. crassa [48]. Strains carrying deletions of the other identified aldehyde dehydrogenase genes ( $\triangle$ NCU03076, $\triangle$ NCU03415, $\triangle$ NCU09648 or $\triangle$ NCU00936) did not show a growth phenotype that differed from the wild-type strain when exposed to furfural.

The AHD-2 protein is the closest homolog of the mitochondrial aldehyde dehydrogenase from yeast, Ald4 (e value $4 \mathrm{e}^{-175}$ ). This result was also supported by a bioinformatics-based prediction for mitochondrial localization as determined with pSORTII [49] and MitoProt II [50], and close structural homology ( $P$ value $\left.4.5 \times 10^{-124}\right)$ 
to the human mitochondrial aldehyde dehydrogenase (PDB structure 1cw3 [51]). To confirm that deletion of ahd-2 resulted in sensitivity to furfural, we targeted the wild-type ahd-2 gene, placed under the regulation of the constitutive tef- 1 promotor, to the his-3 locus in a $\Delta a h d-$ 2 strain. The Ptef1-ahd-2; $\Delta a h d-2$ strain exhibited a significantly shorter lag phase after exposure to $60 \mathrm{mM}$ of furfural, to $2.6 \mathrm{~h}$ (a reduction of $2.2 \mathrm{~h}$ relative to wildtype), and was significantly more tolerant (by $36 \%$ ) than the wild-type to a similar concentration of the chemical (Fig. 1). These data suggest that ahd-2 is involved in sensitivity to furfural.

\section{Attributes of furfural tolerance identified by a hypothesis-based approach}

In an attempt to complement our initial RNA-seq-based approach to identify genes involved in the response to furfural, we employed a hypothesis-driven approach based on the functions of relevant genes predicted to be involved in the process of detoxification or tolerance to furans, particularly furfural or HMF, in S. cerevisiae [18, 19, 39, 52], Escherichia coli [53] and Cupriavidus basilensis HMF14 (a bacterium isolated from enriched HMF) [54] (Additional file 1: Table S4). The homologous $N$. crassa genes were identified by BlastP and the appropriate deletion strains were obtained from the FGSC (Additional file 1: Table S4) and analyzed for their ability to grow on media supplemented with semi-lethal concentrations of $20 \mathrm{mM}$ furfural.

\section{The fir-1 (NCU05580) transporter is involved in tolerance to furfural}

Out of the 25 mutants tested (Additional file 1: Table S4), only one strain exhibited a difference in tolerance to furfural. The deletion strain of the membrane transporter NCU05580, a member of the major facilitator superfamily, exhibited a $\sim 38 \%$ slower growth rate compared to wild-type when cultured in the presence of $60 \mathrm{mM}$ of furfural in solid media (Additional file 1: Table S5). This phenotypic attribute of $\triangle \mathrm{NCU} 05580$ was observed only when the strain was cultured on solid medium. It did not show an increase in the lag phase or inhibition of growth in 96-well plate assays. NCU05580 is a homolog of $S$. cerevisiae FLR1 (fluconazole resistant-1), which has been linked with tolerance to fluconazole [55]. Furthermore, overexpression of FLR1 in S. cerevisiae resulted in enhanced resistance to HMF [18]. Hence, we designated NCU05580 as flr-1 (furfural resistance-1).

We hypothesized that constitutive expression of $f l r-1$ would improve tolerance of $N$. crassa to furfural and perhaps toward other inhibitory compounds. To examine that possibility, we constructed a plasmid with the $f l r-1$ gene under a constitutive promoter $\left(P c p c-1^{\Delta 2 u o r}\right)$. The
Pcpc-1::flr-1 construct fully complemented the slower growth phenotype of the $\Delta f l r-1$ mutant (Additional file 1: Figure S3A). The Pcpc-1::flr-1 strain was screened for sensitivity to furfural at different concentrations compared to wild type. The strain was more tolerant to $60 \mathrm{mM}$ furfural in solid media compared to wild-type, where an improvement of $\sim 60 \%$ in colony growth was evident (Additional file 1: Table S5). When subjected to the 96-well assay, the Pcpc-1::fr-1 strain showed a significantly shorter lag phase when grown in the presence of $60 \mathrm{mM}$ furfural (1.63 h compared to $4.77 \mathrm{~h}$ in wild-type cells) and significantly more tolerance (an increase of $27 \%$ at $60 \mathrm{mM}$ furfural) (Fig. 1). Since no significant difference was evident at lower concentrations of furfural, we monitored the expression level of $f l r-1$ by real-time PCR. After exposure of wild-type cells to $120 \mathrm{mM}$, but not to 30 or $60 \mathrm{mM}$ furfural, the expression of $f l r-1$ was reduced by $\sim 70 \%$, as compared to the control (Additional file 1: Figure S3B). Based on the cumulative results obtained, we concluded that $f l r-1$ is relevant to tolerance toward furfural and that a strain that constitutively expresses $f l r-1$ can improve the growth on furfural.

\section{A random promotor-based tagged mutagenesis approach for identification of genes involved in tolerance to furfural} One of the strategies to generate furfural-tolerant $S$. cerevisiae mutants has been by overexpression of genes involved in the detoxification process [52]. Based on the data provided by constitutive expression of ahd -2 and $f l r-$ 1 , reported in this study, we hypothesized that a similar approach could be a possible key to improve our understanding of molecular pathways of tolerance in $N$. crassa. To do so, we produced a random integrative library of $N$. crassa, based on the integration of pAZ11 that contained the constitutive $c p c-1^{\Delta 2 \text { uorf }}$ promotor, linked with a hygromycin selection marker. After transformation, the colonies were screened for the ability to grow on medium containing hygromycin overlaid with medium containing a high concentration $(90 \mathrm{mM})$ of furfural. Among the transformants obtained, we further analyzed two strains, T112 and T361, which repeatedly exhibited tolerance to the furan in the initial 96-well plate screen.

\section{NCU02488 is involved in tolerance to furfural}

The transformant T112 showed a shorter lag phase when exposed to 15 and $30 \mathrm{mM}$ furfural, to 0.36 and $1.22 \mathrm{~h}$ (a decrease of 0.6 and $0.94 \mathrm{~h}$ relative to wild-type cells, respectively), but not at a concentration of $60 \mathrm{mM}$ (Fig. 1). To further characterize the effect of furfural on the early stages of fungal growth, we examined asexual spore germination rates in the presence of the compound. Addition of $30 \mathrm{mM}$ of furfural to conidial suspensions of T112 did not change the germination rate, 
which was similar to the wild-type control after 4 and $6 \mathrm{~h}$ (Fig. 2). In contrast, hyphal growth of wild-type cells of $N$. crassa was more sensitive to the furan as compared to the T112 strain when analyzed in the 96-well plate assay (Fig. 1).

We previously found that the addition of HMF conferred changes in the intracellular and secreted protein profile in the white-rot fungus Pleurotus ostreatus [56]. Hence, we examined if the transformant T112 conferred any detectable changes in intracellular and secreted protein fractions of $N$. crassa after exposure to furfural. To test this, we extracted these fractions after addition of 60 and $120 \mathrm{mM}$ furfural and compared the protein profiles to those of the wild type. Although intracellular protein profiles were similar, in the secreted fraction a change in a $\sim 75 \mathrm{kDa}$ band was observed, which accumulated in correlation with an increase in furfural concentration in wild-type cells. An opposite trend (a decrease in the band intensity at higher concentrations) was observed in the T112 strain (Additional file 1: Figure S4). The bands were sequenced by MS and identified as having high coverage of the same protein, encoded by NCU05137. This gene was previously identified as encoding a non-anchored cell wall protein-1 (ncw-1) [40]. NCU05137 is conserved in the genomes of a number of filamentous ascomycete fungi, and the deletion of $n c w-1$ has been associated with increased endoglucanase and glucosidase activities [29]. When re-examining our RNA-seq data, we observed that $n c w-1$ exhibited a fourfold decrease in expression after exposure to furfural (Additional file 1: Table S6). However, real-time PCR analysis results showed similar $n c w-1$ expression levels with or without furfural in both wildtype and the T112 strains. While there was no significant difference between the germination rates of the $\Delta n c w-1$ mutant and the parental wild-type strain after $4 \mathrm{~h}$ in the presence of $30 \mathrm{mM}$ of furfural, the $\Delta n c w-1$ mutant germinated $50 \%$ faster at the $6 \mathrm{~h}$ time point (Fig. 2). The $\Delta n c w-1$ exhibited similar tolerance to furfural as the wild type in solid media and in the 96-well assays (Fig. 1).

To identify the location of the pAZ11 insertion in transformant T112, the integration site was identified by genome sequencing, and localized in the first exon of NCU02488, a gene encoding for a predicted hypothetical protein (Fig. 6). We then analyzed the tolerance of the $\triangle N C U 02488$ strain to furfural. The deletion mutant had a significantly shorter lag phase after exposure to $30 \mathrm{mM}$ and $60 \mathrm{mM}$ furfural, to 0.09 and $2.34 \mathrm{~h}$ (reduction of 2.1 and $2.4 \mathrm{~h}$ relative to wild type, respectively) and was significantly more tolerant to $60 \mathrm{mM}$ furfural by $28 \%$ (Fig. 1), as determined by the 96 -well plate assay. Interestingly, the changes in NCW-1 protein levels in the $\triangle$ NCU02488 strain were similar to T112 mutant (Additional file 1: Figure S4).

Transformant T361 exhibited an increase in tolerance to furfural. The transformant had a shorter lag phase of $2.33 \mathrm{~h}$ after exposure to $60 \mathrm{mM}$ furfural (significant reduction of $2.1 \mathrm{~h}$ relative to wild type), but was not altered in relative growth rate as determined in the 96-well screen (Fig. 1). On solid medium, the tolerance of transformant T361 to $60 \mathrm{mM}$ furfural was increased by $65 \%$ relative to wild-type (Additional file 1: Table S5). The mutant exhibited improved germination rate after addition of $30 \mathrm{mM}$ of furfural, to $49 \%$ after $4 \mathrm{~h}$ (wild-type germination rate was $16 \%$ ) and no inhibition was apparent after $6 \mathrm{~h}$ (wild-type germination rate was $47 \%$ ) (Fig. 2).
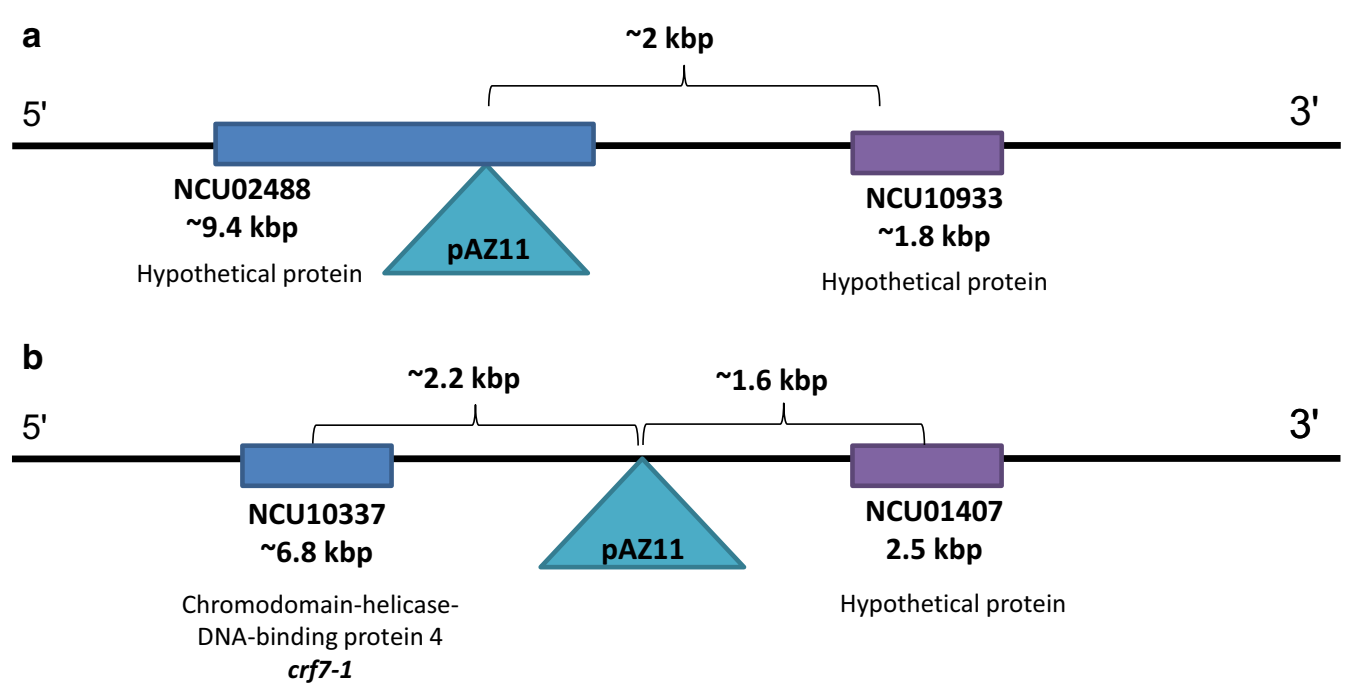

Fig. 6 Schematic representation of plasmid insertion in transformants T112 (a) and T361 (b) 
The genome of transformant T361 was sequenced to locate the pAZ11 insert, which was integrated $\sim 1.6 \mathrm{kbp}$ upstream of NCU01407 (Fig. 6). The NCU01407 gene encodes a hypothetical protein, with a zinc finger $\mathrm{C} 3 \mathrm{H} 1-$ type profile (IPR000571). The $\triangle$ NCU01407 strain was only available as a heterokaryon and we were not able to produce a homokaryon with microconidia enrichment or sexual crossing. However, the heterokaryotic deletion strain had a significantly shorter lag phase after exposure to 15,30 and $60 \mathrm{mM}$ furfural, to $0.15,0.56$ and $1.63 \mathrm{~h}$ (a reduction of $0.8,1.6$ and $3.15 \mathrm{~h}$ relative to wild type, respectively) (Fig. 1), and was significantly (30\%) more tolerant to $60 \mathrm{mM}$ furfural (Fig. 1). Unlike in the case of the T112 strain, no noticeable changes were observed in the profiles of intracellular or secreted proteins.

\section{Discussion}

The means for addressing the challenge of inhibitors produced during pretreatment of biomass were suggested to be a combination of introducing advanced detoxification methods, effective hydrolytic processes as well as molecular engineering of resistant phenotypes [57]. In this study, we focused on the ascomycete fungus $N$. crassa as a potential source of genes for yeast strain improvement. This fungus is able to grow on burned trees and is thus exposed to the inhibitory compound furfural in its natural habitat [25], even though the $\mathrm{IC}_{50}$ for furfural was similar in N. crassa and yeast [38]. To understand the molecular and metabolic basis and to identify new genes involved in tolerance toward furfural in $N$. crassa, we used a combination of approaches, including RNA-seq, hypothesis-driven reverse genetics and random promotor insertional mutagenesis.

We calibrated a high-throughput 96-well assay to measure the level of sensitivity of $N$. crassa to furfural, focusing on two main parameters; the delay in lag phase, and inhibition in relative growth, representing early colony inhibition and growth arrest, respectively. Furfural also inhibited fungal conidial germination. The screens of different mutants in this study showed that these three parameters, germination, lag phase and growth inhibition, do not overlap and different genes can be involved in each process. Among the genes we identified as relevant to furfural tolerance, $n c w-1$ has an effect only during germination, ahd-2 and $f l r-1$ improved tolerance during hyphal growth, while $c r e-1$ and NCU02488 were involved in both phases.

RNA-seq analyses revealed that a total of 936 genes were differentially expressed after exposure to furfural. This transcriptional response was similar to other organisms, such as S. cerevisiae $[19,58,59]$ and the ethanol producing Gram-negative bacterium Zymomonas mobilis [60]. Comparing the response between furfural and
HMF (Additional file 1: Figure S2) showed that N. crassa responded differently to each furan, and only a small number of the altered genes overlapped. Furfural affected the expression of 3.5-fold more genes than HMF, in either an upregulated or downregulated manner. These data suggest a more global response of $N$. crassa toward furfural, perhaps since it is more specialized in metabolizing a compound that can be found in its natural habitat [25].

The RNA-seq results showed that the GO term of "carbohydrate metabolic process" was affected by furfural. Likewise, comparative proteomic analysis of a new furfural-adapted Pichia stipitis strain (Y7-1) found that the most differentially expressed proteins are involved in carbohydrate metabolism [61]. Lactobacillus brevis S3F4 showed strong resistance to fermentation inhibitors such as furfural and ferulic acid under CCR conditions when grown on xylose [62]. Increased tolerance to furfural was observed in $N$. crassa when CMC was used as carbon source, coupled with improved in vitro furfural degradation utilizing $\mathrm{NADH}$ as a co-factor. A similar response was observed in a cre-1 mutant, which bears a deletion in a key transcription factor important for regulating CCR [30, 34, 43-47]. N. crassa has significant cellulolytic activity $[29,43,63]$ and our data indicate that under these conditions, it is more tolerant to furfural.

Furfural was shown to inhibit important metabolic enzymes including aldehyde dehydrogenase [39, 64]. Using a reverse genetics approach, we found that a deletion mutant of an aldehyde dehydrogenase gene (ahd2) conferred sensitivity to furfural. ahd-2 is the closest homolog of Ald4 in S. cerevisiae, which is able to reduce HMF and furfural utilizing NADH as a co-factor [39], and was induced in the transcriptome immediately after exposure to HMF [19]. Constitutive expression of ahd-2 conferred improved tolerance to furfural, while the deletion of Ald4 in S. cerevisiae did not affect the growth with either furfural or HMF, and the overexpression strain failed to grow in the presence of HMF [39]. The involvement of aldehyde dehydrogenases in tolerance toward furfural seems to be phylogenetically conserved, as they are important attributes in tolerance to furans both in yeast and N. crassa. AHD-2, unlike Ald4 from S. cerevisiae, is not redundant in its role in furfural tolerance by other aldehyde dehydrogenases. This result emphasizes the conserved, but not identical mode of resistance, between these two fungi.

A hypothesis-based approach was used to screen potential genes that were previously reported to have an effect on tolerance to furfural. A strain in which $f l r-$ 1 (NCU05580) had been deleted exhibited slower growth coupled with increased sensitivity to furfural. FLR-1 harbors major a facilitator superfamily (MFS) domain (IPR020846), whose members function as transporters. 
Constitutive expression of $f l r-1$ resulted in an increased tolerance to high concentrations of furfural. As $f l r-1$ expression is downregulated at high concentrations of furfural, it is conceivable that Pcpc1::flr-1 "masks" that effect conferring improved tolerance. FLR-1 is the closest homolog to Flr1 in S. cerevisiae, whose overexpression resulted in enhanced resistance to the phenolic inhibitor coniferyl aldehyde and to HMF [18]. $f l r-1$ is also a homolog of the Tpo1p, a transporter of polyamines. However, unlike $f l r-1, T P O 1$ expression was induced by HMF during the lag phase in S. cerevisiae [19]. Overall, we propose that further analysis of $f t r-1$ can improve our understanding of the fungal cellular response to furfural. Furthermore, as the FLR 1 and TOP1 homologs are linked to tolerance to HMF, but not to furfural in S. cerevisiae, $N$. crassa flr-1 could well be a valid candidate for heterologous expression in yeast.

The fact that constitutive expression of ahd-2 and $f l r-$ 1 conferred improved tolerance to furfural encouraged us to further exploit the possibility of using promotortagged random mutagenesis to generate strains with improved tolerance to this furan. The transformant T112 had a significantly shorter lag phase, but increased inhibition in relative growth, after exposure to furfural. The insertion was within the NCU02488, which encodes a small hypothetical protein of 188 aa, which is specific to $N$. crassa and closely related species, such as $N$. tetrasperma and Sordaria macrospora. The $\triangle$ NCU02488 mutant also exhibited a decreased lag phase but, unlike T112, was more tolerant in relative growth to furfural. The transformant T112 exhibited a decrease in NCW-1 accumulation in the secretome; the $\Delta n c w-1$ strain was previously shown to have increased endoglucanase and glucosidase activities [29]. Via RNA-seq analyses, we showed that these same activities decreased by fourfold after exposure to furfural, suggesting yet another link between CCR and furfural tolerance in N. crassa. A $n c w-1$ deletion strain had similar growth sensitivity to furfural as the wild-type strain, but improved germination after exposure to the compound. This result suggests that improved tolerance toward furfural during germination in T112 may be partially mediated by NCW-1. Similar to T112, transformant T361 had a significantly shorter lag phase after exposure to furfural. The plasmid insertion was upstream of NCU01407, which encodes a hypothetical protein of 495 aa. A $\triangle$ NCU01407 mutant conferred increased tolerance to furfural and decreased lag phase. The gene harbors an InterPro domain of zinc finger C3H1-type profile (IPR000571). In $N$. discreta, the NCU01407 ortholog (NEUDI_17858) has been designated as an SWI-SNF chromatin-remodeling complex protein, suggesting that tolerance to furfural may involve the chromatin-remodeling complex.
This study presents different and complementary approaches to identify novel genes linked to furfural resistance in $N$. crassa, during which we managed to reveal the involvement of six genes. Among them only two, ahd-2 and $n c w-1$, were differentially expressed after exposure to furfural (Additional file 1: Table S6). Four of the genes were novel targets to furfural tolerance, and only flr- 1 and ahd-2 have homologs in S. cerevisiae, previously reported to be involved in resistance to HMF, suggesting a different mode of tolerance to furans in these two fungi. Screening deletion mutants of genes that were differentially affected by furfural, revealed that, similar to yeast [39], N. crassa has a redundancy in genes relevant to tolerance mechanisms. Using both hypothesis-driven and random mutagenesis approaches, we were able to identify additional attributes and to improve our understanding regarding the genetic mechanism of tolerance.

\section{Conclusions}

The results presented here demonstrate that furfural inhibits N. crassa in two modes; it delayed conidial germination and conferred mycelium growth arrest. The transcriptional response to furfural was similar to yeast, with a more global reaction toward furfural than to HMF. The RNA-seq results led us to link the response to carbohydrate metabolism and cre-1, as well as the aldehyde dehydrogenase ahd-2. In the hypothesis-based screen in which known genes were investigated, we identified the $f l r-1$ transporter, and in random promotor mutagenesis we identified NCU02488 and NCU01407. We propose that these newly identified genes can be heterologously expressed in yeast to improve tolerance to furfural. We also propose that a similar research outline, as presented in this study, could be utilized to identify novel resistance attributes not only for furans but to other toxic chemicals and in other organisms.

\section{Materials and methods \\ Fungal growth conditions}

General procedures and media used in the handling of $N$. crassa have been previously described [21] or are available through the FGSC (http://www.fgsc.net/Neurospora /NeurosporaProtocolGuide.htm). Conidial germination assays was performed as previously described [65].

Neurospora crassa strains used in this study are specified in Additional file 1: Table S7. Vogel's minimal medium [21] was used in this study, supplemented with $1.5 \%(\mathrm{w} / \mathrm{v})$ sucrose $(\mathrm{VgS})$ or other carbon sources if mentioned otherwise. When required, $1.5 \%$ agar was added. For restricting $N$. crassa growth, Vogel's minimal medium was supplemented with FGS ( $2 \%$ L-sorbose, $0.05 \%$ glucose and $0.05 \%$ fructose). When required, the medium was supplemented with $100 \mu \mathrm{g} / \mathrm{ml}$ histidine 
(Sigma-Aldrich) and/or $10 \mu \mathrm{g} / \mathrm{ml}$ hygromycin B (Calbiochem, Riverside, CA, USA). Throughout the study, we used different concentrations of furfural (2-furaldehyde 99\%, Sigma-Aldrich) and HMF (5-hydroxymethyl furfural $\geq 99 \%$, Sigma-Aldrich).

\section{Growth of $N$. crassa in 96-well plate format}

Neurospora crassa was grown in 96-well plates as described by Lopez-Moya et al. [66]. Briefly, the growth of the different strains was followed using 96-well plates (TC microwell 96F, Thermo Fisher Scientific, Denmark). Conidia $\left(2 \times 10^{6}\right.$ spores $\left./ \mathrm{ml}\right)$ were inoculated into $200 \mu \mathrm{l}$ of liquid VgS media with or without furfural, per well. Plates were incubated stationary at $34{ }^{\circ} \mathrm{C}$ in a Synergy HTX Multi-Mode Microplate Reader (BioTek, Winooski, USA); absorbance (490 nm) was measured every $15 \mathrm{~min}$ for $20-21 \mathrm{~h}$. The blank controls contained media with the relevant concentrations of furfural without conidia. For calculations, we subtracted the blank controls and the absorbance at time zero from the relevant experimental samples. Experiments were repeated at least six times, in triplicate.

\section{Enzymatic reaction for degradation of furfural in vitro}

Furfural depletion coupled with $\mathrm{NAD}(\mathrm{P}) \mathrm{H}$ was measured according to Liu et al. [39]. $N$. crassa strains were grown for $16 \mathrm{~h}$ in $100 \mathrm{ml}$ Erlenmeyer flasks containing $20 \mathrm{ml}$ of medium. Mycelial samples were disrupted using a Bead Beater (BioSpec Products, Inc., Bartlesville, OK, USA) in $500 \mu \mathrm{l}$ of $100 \mathrm{mM}$ potassium phosphate buffer $(\mathrm{pH}=7)$. The homogenates were centrifuged for $1 \mathrm{~min}$ at $4000 \times g$ at $4{ }^{\circ} \mathrm{C}$. The protein concentration of the clear lysate was determined using the BioRad protein assay kit (BioRad, Hercules, CA, USA). A $30 \mu \mathrm{l}$ sample of lysate was used for each reaction. After the $\mathrm{NAD}(\mathrm{P}) \mathrm{H}$ was added to the protein lysate, the activity was assayed spectrophotometrically at $340 \mathrm{~nm}\left(\varepsilon 340=6220 \mathrm{M}^{-1} \mathrm{~cm}^{-1}\right)$ with $10 \mathrm{mM}$ furfural in $100 \mathrm{mM}$ of potassium phosphate buffer. The assay was conducted in a total volume of $200 \mu \mathrm{l}$, in microtiter plates, at $30{ }^{\circ} \mathrm{C}$, and changes in absorption were monitored for $15 \mathrm{~min}$, using the Microplate Reader. The data from controls without furfural, as well as samples that were treated at $95{ }^{\circ} \mathrm{C}$ for 5 min were subtracted from the treatments. An enzyme unit was defined as the amount of enzyme depleting $1 \mu \mathrm{mol}$ of $\mathrm{NAD}(\mathrm{P}) \mathrm{H}$ per minute per mg protein. The experiments were performed in three biological replicates (each treatment was composed of three culture flasks and the experiment was repeated on three different dates).

\section{RNA-seq data analysis}

Strain FGSC 2489 was grown on VgS slants for 7 days. Conidia were inoculated into $9 \times 100 \mathrm{ml}$ fresh $\mathrm{VgS}$ for each concentration of furan to a final concentration of $1 \times 10^{6}$ per $\mathrm{ml}$ and grown at $30^{\circ} \mathrm{C}$ for $16 \mathrm{~h}$, at constant light and shaking $(200 \mathrm{rpm})$. The mycelia were washed 2 times with $100 \mathrm{ml}$ minimal medium lacking sucrose and were re-suspended into fresh $\mathrm{VgS}$ containing $10 \mathrm{mM}$ furfural or $\mathrm{HMF}$ for $4 \mathrm{~h}$, at $30{ }^{\circ} \mathrm{C}$, in constant light and shaking (200 rpm). DMSO (1.0\%, v/v) was used as a solvent control. Four hours after inoculation, three samples were each filtered through a Whatman \#1 filter and dried to completion at $75{ }^{\circ} \mathrm{C}$ overnight for biomass measurements. Mycelial mass was reduced to $35 \%(\mathrm{w} / \mathrm{w})$ for furfural and 30\% (w/w) for HMF. An additional three replicates of mycelia were filtered through Whatman paper and snap frozen in liquid nitrogen for RNA extraction.

Total RNA was isolated from the frozen tissue by the Trizol-Phenol-Chloroform method (Thermo Fisher Scientific). The extract was digested with TURBO DNAse (Life Technologies). The poly(A) + mRNA was purified from $10 \mu \mathrm{g}$ total RNA using Dynabeads oligo(dT) magnetic beads (Life Technologies). The mRNA was chemically fragmented using the Ambion RNA fragmentation kit (Life Technologies). The Illumina TruSeq kit was employed to generate the cDNA libraries with indexing adapters essentially following the manufacturer's proto$\mathrm{col}$. The cDNA was size fractioned by gel electrophoresis to $200 \mathrm{bp}$ and then amplified by PCR. The cDNA libraries were sequenced as $50 \mathrm{bp}$ single-end reads on an Illumina HiSeq 2000 platform.

Low quality reads with base calls having a $Q$ value $<20$ were removed using the FASTX toolkit (http://hanno nlab.cshl.edu/fastx_toolkit/download.html) and the filtered reads were mapped to predicted transcripts from the $N$. crassa OR74A genome v12 using Tophat v2.04 [67]. Expression values were normalized as FPKM with cufflinks v2.02 [68] using compatible hits as a normalizing option corrected for fragment and multiple hit biases to the genome. Individual genes that had a differential expression $\log 2>1.0$ and an adjusted $P$ value $<0.01$ after a multiple testing correction using Benjamini-Hochbergprocedure were considered significantly expressed genes using the cuffdiff component of cufflinks v2.02 [68]. Significantly expressed genes were used for hierarchical clustering with Cluster 3.0 [69]. Genes were log transformed, normalized across all conditions and centered on a geometric mean on a per gene basis. Clustering was performed as an average linkage with an uncentered correlation as the similarity metric. Whole RNAseq libraries were clustered by Euclidean distance using a variance-stabilizing transformation module in DEseq v1.14. SRA accession: PRJNA541531.

Functional analysis of differentially expressed genes was based on Gene Ontology (GO) groups as annotated by the Blast2GO v2.8 package [70]. A BLASTP of the $N$. 
crassa OR74A protein database to the non-redundant protein database https://blast.ncbi.nlm.nih.gov/ was generated to create a reference annotation GO term file for FGSC2489. Enrichment tests for GO terms were determined by a one-tailed Fishers exact test with a multiple testing correction cutoff of 0.05 .

\section{Gene expression analyses}

The RNA samples were purified with the RNeasy Plant Mini Kit (Qiagen, Hilden, Germany) and then treated with the DNA-free kit (Ambion). $1 \mu \mathrm{g}$ of purified RNA was used for cDNA synthesis utilizing super-script II RNase $\mathrm{H}$ reverse transcriptase (Invitrogen, Carlsbad, CA, USA). Relative quantification of the transcript abundance was performed using an ABI StepOnePlus Real-Time PCR sequence detection system and software (Applied Biosystems). The PCR contained 20 ng of total cDNA and $300 \mathrm{nM}$ oligonucleotide primers (Additional file 1: Table S8), $\beta$-tubulin as endogenous control [71]. Amplification data were compared on the basis of the of $\Delta \mathrm{CT}$ method and presented as $2^{-\Delta C T}$ or $\Delta \Delta C T$ method and presented as $2^{-\Delta \Delta C T}$.

\section{Construction of Ptef1-ahd-2-gfp}

A PCR fragment was amplified from FGSC 2489 genomic DNA with the primers NCU00378_XbaI_F and NCU00378_PacI_R (Additional file 1: Table S8) using Phusion DNA polymerase (NEB \# M0530). The final product was subjected to PCR purification with Qiaquick PCR kit (Catalog \# 28104) and cloned into the $\mathrm{pCR}^{\circledR}$ vector (Invitrogen \# 44-0302) according to the manufacturer's protocol. The NCU00378 insert was excised from the vector with $X b a \mathrm{I}$ and $P a c \mathrm{I}$ and cloned into a modi-

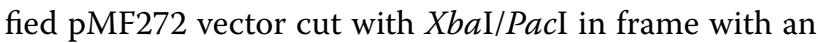
eGFP reporter ORF and flanked by tef-I promoter and $c c g-1$ terminator sequences from pMF272 [72]. The deletion strains for NCU00378 (FGSC 12919) were crossed with FGSC 6103 to create an NCU00378 deletion in a his $3^{-}$background. Progeny were genotyped by Phire Plant Direct PCR (Thermo Scientific \# F-130WH) on conidia with the primers Hphp and NCU00378_3r (Additional file 1: Table S8).

Transformation was performed by electroporation according to a protocol available at the FGSC or as modified by Ziv and Yarden [73]. Conidia from the selected transformants were genotyped by PCR for the hygromycin cassette and also for the NCU00378-GFP construct with the primers NCU00378_F and pMF272_Rev (Additional file 1: Table S8).

\section{Construction of Pcpc-1 ${ }^{\Delta 2 u o r f}$-flr-1}

To construct the $f l r-1$ gene with constitutive expression under $P c p c-1^{\Delta 2 u o r f}$, the promotor was amplified from
pMP6 [74] with primers pMP6-181F and pMP6-11742R. The NCU05580 gene along with its 3 ' flank was amplified from genomic DNA of $N$. crassa with NCU05580-2340R and NCU05580-25F linker (with linker to Pcpc-1 $1^{\Delta 2 u o r f}$ from pMP6) (Additional file 1: Table S8). The $5^{\prime}$ flank of flr-1 was amplified from genomic DNA with NCU05580637F and NCU05580-54R linker (with linker to -Pcpc$1^{\Delta 2 u o r f}$ ) (Additional file 1: Table S8). The three segments were joined together using the Phusion ${ }^{\mathrm{TM}}$ High-Fidelity PCR Master Mix (Thermo Scientific, USA). The amplified construct was cloned into pDRIVE and designated pDF2. pDF2 was digested with XbaI and SmaI and the resulting segment was then co-transformed with pCZ67 (containing the his-3 gene for selection) into $\Delta k u 80$; $\Delta$ his $3^{-}$to replace the existing copy of NCU05580. For complementation, pDF2 was transformed into the $\Delta f l r$ 1; $\Delta$ his $3^{-}$strain. The selection of the transformants was based on their ability to grow without histidine, followed by verification of the insertion by PCR.

\section{Promotor-based tagged mutagenesis}

pAZ11 contains Pcpc-1 $1^{\Delta 2 \text { uorf }}$ from pMP6, along with the hygromycin phosphotransferase gene, from pCSN44. pAZ11 was linearized with ApaI and the random mutagenesis procedure was performed using electroporation, into the wild-type strain (FGSC \#987). Conidia subjected to transformation were then plated on Vogel + FGS amended with hygromycin. After the colonies began to form the plates were overlaid with Vogel + FGS supplemented with $90 \mathrm{mM}$ furfural. Emerging colonies were further analyzed for their tolerance to furfural.

\section{Secreted proteins profiles}

Twenty milliliters of conidia $\left(2 * 10^{5}\right.$ spores $\left./ \mathrm{ml}\right)$ were used to inoculate $100 \mathrm{ml}$ Erlenmeyer flasks containing $\mathrm{VgS}$ and grown for $17 \mathrm{~h}, 150 \mathrm{rpm}$ at $34^{\circ} \mathrm{C}$. The relevant cultures were than supplemented with 60 or $130 \mathrm{mM}$ of furfural and were grown for additional $3.5 \mathrm{~h}$. For extracellular protein analyses, culture fluids were filtered through Whatman No. 1 filter paper followed by an additional filtration step using $0.45-\mu \mathrm{m}$ mixed cellulose ester filter paper (Whatman, Buckinghamshire, UK). Each sample was then concentrated using an Amicon ${ }^{\circledR}$ Ultra 0.5/ Ultra 15 (Millipore, Billerica, MA, USA) system and supplemented with complete (Roche Applied Science, Mannheim, Germany), after the concentration process. The protein concentration was determined using the BioRad protein assay kit (BioRad, Hercules, CA, USA). The proteins were separated and visualized with Coomassie R-250 (0.125\%). Each sample was subsequently analyzed by HPLC/mass spectrometry/mass spectrometry (LCMS/MS) in an Orbitrap (Thermo Scientific, Waltham, 
MA, USA) mass spectrometer and identified by Sequest 3.31 software against the genome of $N$. crassa OR-74A in NCBI. Protein identification was performed by the Smoler Proteomics Center of The Israel Institute of Technology (Technion).

\section{Sequencing of transformants T112 and T361 \\ Library construction and sequencing}

DNA-Seq was performed as previously described [75] with the following modifications: 300-600 ng of gDNA was sheared using the Covaris E220X sonicator (Covaris, Inc., Woburn, MA, USA). End repair was performed in $80 \mathrm{ul}$ reaction at $20{ }^{\circ} \mathrm{C}$ for $30 \mathrm{~min}$. Following Agencourt AmPURE XP beads cleanup (Beckman Coulter, Inc., Indianapolis, IN, USA) in a ratio of $0.75 \times$ Beads/ DNA volume, adenine bases were added to both $3^{\prime}$ ends followed by adapter ligation in a final concentration of $0.125 \mu \mathrm{M}$. An SPRI bead cleanup in a ratio of $0.75 \times$ beads/DNA volume was performed, followed by 8 PCR cycles using $2 \times$ KAPA HiFi ready mix (Kappa Biosystems, Inc. Wilmington, MA, USA) in a total volume of $25 \mu \mathrm{l}$ with the following program: $2 \mathrm{~min}$ at $98^{\circ} \mathrm{C}, 8$ cycles of $20 \mathrm{~s}$ at $98{ }^{\circ} \mathrm{C}, 30 \mathrm{~s}$ at $55{ }^{\circ} \mathrm{C}, 60 \mathrm{~s}$ at $72{ }^{\circ} \mathrm{C}$ following by $72{ }^{\circ} \mathrm{C}$ at $10 \mathrm{~min}$.

Libraries were evaluated by Qubit and TapeStation. Sequencing libraries were constructed with barcodes to allow multiplexing of nine samples in one lane of Illumina HiSeq 2500 V4 instrument, using paired end $125 \mathrm{bp}$ protocol. The output was $\sim 23$ million reads per sample. Sequencing depth was homogenous across samples. Fastq files for each sample were generated by the usage of Illumina bcl2fastq v2.17.1.14 software.

\section{Analysis of sequence data}

A reference genome which is based on N. crassa OR74 genome (FungiDB [76], release 30) and the given plasmid, pAZ11, as an additional contig was prepared. Speedseq framework [77] (version 0.0.3a) was used for the genome analysis to detect structural variants. The framework includes the following steps: (i) align-reads for each sample were mapped independently using BWA-MEM [78] to the reference genome. Duplicate reads were marked by SAMBLASTER [79]. 97\% uniquely mapping rates was observed. The mapped reads yielded a mean coverage depth of $20 \times$ per sample and above $99 \%$ of the genome is covered with more than $25 \times$. (ii) sv-run LUMPY [80] on all samples. This pipeline infers genomic variations: single nucleotide variants (SNPs), indels, and structural variants (SVs).

\section{Bioinformatics analysis}

To detect events that are related to the plasmid insertions, we extracted variants which were involved with the plasmid contig. The evidence for the insertion is supported by (1) detected breakpoint within the reads (by split reads) and (2) discordant read pairs for which one of the pairs maps to the plasmid. Mind The Gap [81] was used to validate the plasmid events by assembly of insertion for detected breakpoints.

DNA-seq and relevant bioinformatics of the transformants were carried out at the Nancy and Stephen Grand Israel National Center for Personalized Medicine, Rehovot, Israel.

\section{Supplementary information}

\section{Supplementary information accompanies this paper at https://doi. org/10.1186/s13068-019-1550-4}

\begin{abstract}
Additional file 1: Figure S1. Inhibitory effect of furfural on N. crassa wild-type in solid media. Figure S2. GO terms associated with biological processes that are up regulated in N. crassa, upon exposure to HMF.

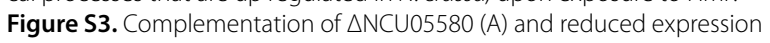
of NCU05580 after exposure to $120 \mathrm{mM}$ of furfural. Figure S4. Profiles of secreted proteins obtained from wild-type, T112 and $\triangle$ NCU02488 cultures grown in the presence of furfural. Table S2. Notable genes whose expression levels were increased following exposure to furfural. Table S3. Summary of genes that had the highest up- or downregulation in response to furfural or HMF and were screened for tolerance to the furans. Table S4. Summary of genes whose deletion strains were analyzed in a hypothesis-driven approach. Table $\mathbf{S 5}$. Inhibition in relative growth of different mutant strains in the presence of $60 \mathrm{mM}$ of furfural, on solid media. The presented results were normalized to wild-type. The values and standard errors represent the average of at least three biological replicates. Table S6. Summary of genes identified in this study that are involved in tolerance to furfural. Table S7. Strains of N. crassa used in this study. Table S8. Oligonucleotides used in this study.
\end{abstract}

Additional file 2: Table S1. Differentially expressed genes by RNA-seq in N. crassa, after exposure to $10 \mathrm{mM}$ furfural or $10 \mathrm{mM} \mathrm{HMF}$

Additional file 3: Table S9. Gene Ontology terms for biological processes with significantly over expressed genes upon exposure to furfural.

\section{Acknowledgements}

We thank Avihai Zolti for providing pAZ11.

\section{Authors' contributions}

DF and DJK carried out the experimental studies and drafted the manuscript. AC carried out the experimental studies. YH, OY, and NLG conceived the study, and participated in its design and coordination, and helped to draft the manuscript. All authors read and approved the final manuscript.

\section{Funding}

This study was supported by the Israel Science Foundation and a US-Israel Binational Science Foundation Grant.

Ethics approval and consent to participate Not applicable.

\section{Competing interests}

The authors declare that they have no competing interests.

\section{Author details}

${ }^{1}$ Department of Plant Pathology and Microbiology, The R.H. Smith Faculty Agriculture, Food and Environment, The Hebrew University of Jerusalem, 7600001 Rehovot, Israel. ${ }^{2}$ Department of Plant and Microbial Biology, University of California, Berkeley, Berkeley, CA 94720, USA. ${ }^{3}$ Environmental Genomics and Systems Biology Division, The Lawrence Berkeley National Laboratory, 1 Cyclotron Road, Berkeley, CA 94720, USA. 
Received: 16 May 2019 Accepted: 24 August 2019

Published online: 04 September 2019

\section{References}

1. Carroll A, Somerville C. Cellulosic biofuels. Annu Rev Plant Biol. 2009;60:165-82.

2. Almeida JRM, Bertilsson M, Gorwa-Grauslund MF, Gorsich S, Liden G. Metabolic effects of furaldehydes and impacts on biotechnological processes. Appl Microbiol Biotechnol. 2009;82:625-38.

3. Zheng Y, Shi J, Tu M, Cheng Y-S. Principles and development of lignocellulosic biomass pretreatment for biofuels. In: Advances in bioenergy. Elsevier; 2017. p. 1-68.

4. Bhutto AW, Qureshi K, Harijan K, Abro R, Abbas T, Bazmi AA, et al. Insight into progress in pre-treatment of lignocellulosic biomass. Energy. 2017:122:724-45.

5. Klinke HB, Thomsen AB, Ahring BK. Inhibition of ethanol-producing yeast and bacteria by degradation products produced during pre-treatment of biomass. Appl Microbiol Biotechnol. 2004;66:10-26.

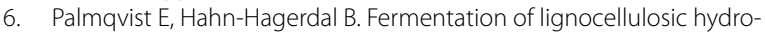
lysates. II: inhibitors and mechanisms of inhibition. Bioresour Technol. 2000;74:25-33.

7. Taherzadeh MJ, Karimi K. Pretreatment of lignocellulosic wastes to improve ethanol and biogas production: a review. Int J Mol Sci. 2008;9:1621-51.

8. Antal MJJ, Leesomboon T, MokWS, Richards GN. Mechanism of formation of 2-furaldehyde from D-xylose. Carbohydr Res. 1991;217:71-86.

9. Dunlop AP. Furfural formation and behavior. Ind Eng Chem. 1948;2:204-9.

10. Larsson S, Palmqvist E, Hahn-Hagerdal B, Tengborg C, Stenberg K, Zacchi $\mathrm{G}$, et al. The generation of fermentation inhibitors during dilute acid hydrolysis of softwood. Enzyme Microb Technol. 1999;24:151-9.

11. Lewkowski J. Synthesis, chemistry and applications of 5-hydroxymethylfurfural and its derivatives. Arkivoc. 2005;2001:17

12. Parawira W, Tekere M. Biotechnological strategies to overcome inhibitors in lignocellulose hydrolysates for ethanol production: review. Crit Rev Biotechnol. 2011;31:20-31.

13. Wan C, Li Y. Fungal pretreatment of lignocellulosic biomass. Biotechnol Adv. 2012;30:1447-57

14. Liu ZL. Genomic adaptation of ethanologenic yeast to biomass conversion inhibitors. Appl Microbiol Biotechnol. 2006;73:27-36.

15. Villa GP, Bartroli R, Lopez R, Guerra M, Enrique M, Penas M, et al. Microbial transformation of furfural to furfuryl alcohol by Saccharomyces cerevisiae. Acta Biotechnol. 1992;12:509-12.

16. Lin FM, Qiao B, Yuan YJ. Comparative proteomic analysis of tolerance and adaptation of ethanologenic Saccharomyces cerevisiae to furfural, a lignocellulosic inhibitory compound. Appl Environ Microbiol. 2009;75:3765-76.

17. Heer D, Heine D, Sauer U. Resistance of Saccharomyces cerevisiae to high concentrations of furfural is based on NADPH-dependent reduction by at least two oxireductases. Appl Environ Microbiol. 2009;75:7631-8.

18. Alriksson B, Horváth IS, Jönsson LJ. Overexpression of Saccharomyces cerevisiae transcription factor and multidrug resistance genes conveys enhanced resistance to lignocellulose-derived fermentation inhibitors. Process Biochem. 2010;45:264-71.

19. Ma M, Liu ZL. Comparative transcriptome profiling analyses during the lag phase uncover YAP1, PDR1, PDR3, RPN4, and HSF1 as key regulatory genes in genomic adaptation to the lignocellulose derived inhibitor HMF for Saccharomyces cerevisiae. BMC Genomics. 2010;11:660.

20. Liu ZL. Molecular mechanisms of yeast tolerance and in situ detoxification of lignocellulose hydrolysates. Appl Microbiol Biotechnol. 2011;90:809-25.

21. Davis RH. Neurospora: contributions of a model organism. Oxford: Oxford University Press; 2000

22. Borkovich KA, Alex LA, Yarden O, Freitag M, Turner GE, Read ND, et al. Lessons from the genome sequence of Neurospora crassa: tracing the path from genomic blueprint to multicellular organism. Microbiol Mol Biol Rev. 2004;68:1-108

23. Galagan JE, Calvo SE, Borkovich KA, Selker EU, Read ND, Jaffe D, et al. The genome sequence of the filamentous fungus Neurospora crassa. Nature. 2003:422:859-68.
24. Dunlap JC, Borkovich KA, Henn MR, Turner GE, Sachs MS, Glass NL, et al. Enabling a community to dissect an organism: overview of the Neurospora functional genomics project. Fungal Genom. 2007;57:49-96.

25. Pandit A, Maheshwari R. Life-history of Neurospora intermedia in a sugar cane field. J Biosci. 1996:21:57-79.

26. Turner BC, Perkins DD, Fairfield A. Neurospora from natural populations: a global study. Fungal Genet Biol. 2001;32:67-92.

27. Perkins DD, Turner BC, Barry EG. Strains of Neurospora collected from nature. Evolution. 1976:30:281.

28. Perkins DD, Turner BC. Neurospora from natural populations: toward the population biology of a haploid eukaryote. Exp Mycol. 1988;12:91-131.

29. Tian C, Beeson WT, lavarone AT, Sun J, Marletta MA, Cate JHD, et al. Systems analysis of plant cell wall degradation by the model filamentous fungus Neurospora crassa. Proc Natl Acad Sci. 2009;106:22157-62.

30. Coradetti ST, Xiong Y, Glass NL. Analysis of a conserved cellulase transcriptional regulator reveals inducer-independent production of cellulolytic enzymes in Neurospora crassa. Microbiologyopen. 2013;2:595-609.

31. Yi X, Sun J, Glass NL. VIB1, a link between glucose signaling and carbon catabolite repression, is essential for plant cell wall degradation by Neurospora crassa. PLoS Genet. 2014;10:e1004500.

32. Glass NL, Schmoll M, Cate JHD, Coradetti S. Plant cell wall deconstruction by ascomycete fungi. Annu Rev Microbiol. 2013;67:477-98.

33. Samal A, Craig JP, Coradetti ST, Benz JP, Eddy JA, Price ND, et al. Network reconstruction and systems analysis of plant cell wall deconstruction by Neurospora crassa. Biotechnol Biofuels. 2017;10:225.

34. Coradetti ST, Craig JP, Xiong Y, Shock T, Tian C, Glass NL. Conserved and essential transcription factors for cellulase gene expression in ascomycete fungi. Proc Natl Acad Sci. 2012;109:7397-402.

35. Emerson MR. Chemical activation of ascospore germination in Neurospora crassa. J Bacteriol. 1948;55:327-30.

36. Eilers FI, Sussman AS. Conversion of furfural to furoic acid and furfuryl alcohol by Neurospora ascospores. Planta. 1970;94:253-64.

37. Dogaris I, Gkounta O, Mamma D, Kekos D. Bioconversion of dilute-acid pretreated sorghum bagasse to ethanol by Neurospora crassa. Appl Microbiol Biotechnol. 2012:95:541-50.

38. Greetham D, Zaky AS, Du C. Exploring the tolerance of marine yeast to inhibitory compounds for improving bioethanol production. Sustain Energy Fuels. 2019;3:1545-53.

39. Liu L, Moon J, Andersh BJ, Slininger PJ, Weber S. Multiple gene-mediated $\mathrm{NAD}(\mathrm{P}) \mathrm{H}$-dependent aldehyde reduction is a mechanism of in situ detoxification of furfural and 5-hydroxymethylfurfural by Saccharomyces cerevisiae. Appl Microbiol Biotechnol. 2008;81:743-53.

40. Bowman SM, Piwowar A, Dabbous A, Vierula J, Free SJ. Mutational analysis of the glycosylphosphatidylinositol (GPI) anchor pathway demonstrates that GPI-anchored proteins are required for cell wall biogenesis and normal hyphal growth in Neurospora crassa. Eukaryot Cell. 2006;5:587-600.

41. Ao J, Aldabbous M, Notaro MJ, Lojacono M, Free SJ. A proteomic and genetic analysis of the Neurospora crassa conidia cell wall proteins identifies two glycosyl hydrolases involved in cell wall remodeling. Fungal Genet Biol. 2016;94:47-53.

42. McCluskey K, Wiest A, Plamann M. The Fungal Genetics Stock Center: a repository for 50 years of fungal genetics research. J Biosci. 2010:35:119-26.

43. Znameroski EA, Coradetti ST, Roche CM, Tsai JC, lavarone AT, Cate JHD, et al. Induction of lignocellulose-degrading enzymes in Neurospora crassa by cellodextrins. Proc Natl Acad Sci. 2012;109:6012-7.

44. Ogawa M, Kobayashi T, Koyama Y. ManR, a transcriptional regulator of the $\beta$-mannan utilization system, controls the cellulose utilization system in Aspergillus oryzae. Biosci Biotechnol Biochem. 2013;77:426-9.

45. Yamakawa Y, Endo Y, Li N, Yoshizawa M, Aoyama M, Watanabe A, et al. Regulation of cellulolytic genes by McmA, the SRF-MADS box protein in Aspergillus nidulans. Biochem Biophys Res Commun. 2013;431:777-82.

46. Ziv C, Gorovits R, Yarden O. Carbon source affects PKA-dependent polarity of Neurospora crassa in a CRE-1-dependent and independent manner. Fungal Genet Biol. 2008;45:103-16.

47. Sun J, Glass NL. Identification of the CRE-1 cellulolytic regulon in Neurospora crassa. PLoS ONE. 2011;6:e25654.

48. Sardar P, Kempken F. Characterization of indole-3-pyruvic acid pathwaymediated biosynthesis of auxin in Neurospora crassa. PLoS ONE. 2018;13:e0192293. 
49. Horton P, Park K-J, Obayashi T, Nakai K. Protein subcellular localization prediction with WoLF PSORT. In: Proc 4th Asia-Pacific Bioinforma Conf. 2005. p. 39-48.

50. Claros MG, Vincens P. Computational method to predict mitochondrially imported proteins and their targeting sequences. Eur J Biochem. 1996;241:779-86.

51. Ni L, Zhou J, Weiner H, Hurley TD. Human liver mitochondrial aldehyde dehydrogenase: three-dimensional structure and the restoration of solubility and activity of chimeric forms. Protein Sci. 2008:8:2784-90

52. Petersson A, Almeida JRM, Modig T, Karhumaa K, Hahn-Hägerdal B, Gorwa-Grauslund MF, et al. A 5-hydroxymethyl furfural reducing enzyme encoded by the Saccharomyces cerevisiae ADH6 gene conveys HMF tolerance. Yeast. 2006;23:455-64.

53. Miller EN, Jarboe LR, Yomano LP, York SW, Shanmugam KT, Ingram LO. Silencing of NADPH-dependent oxidoreductase genes (yqhD and dkgA) in furfural-resistant ethanologenic Escherichia coli. Appl Environ Microbiol. 2009;75:4315-23.

54. Koopman F, Wierckx N, de Winde $\mathrm{JH}$, Ruijssenaars HJ. Identification and characterization of the furfural and 5-(hydroxymethyl)furfural degradation pathways of Cupriavidus basilensis HMF14. Proc Natl Acad Sci USA. 2010;107:4919-24.

55. Alarco A-M, Balan I, Talibi D, Mainville N, Raymond M. AP1-mediated multidrug resistance in Saccharomyces cerevisiae requires FLR1 encoding a transporter of the major facilitator superfamily. J Biol Chem. 1997;272:19304-13.

56. Feldman D, Kowbel DJ, Glass NL, Yarden O, Hadar Y. Detoxification of 5-hydroxymethylfurfural by the Pleurotus ostreatus lignolytic enzymes aryl alcohol oxidase and dehydrogenase. Biotechnol Biofuels. 2015;8:11.

57. Taylor MP, Mulako I, Tuffin M, Cowan D. Understanding physiological responses to pre-treatment inhibitors in ethanologenic fermentations. Biotechnol J. 2012;7:1169-81.

58. Li BZ, Yuan YJ. Transcriptome shifts in response to furfural and acetic acid in Saccharomyces cerevisiae. Appl Microbiol Biotechnol. 2010;86:1915-24.

59. Chen Y, Sheng J, Jiang T, Stevens J, Feng X, Wei N. Transcriptional profiling reveals molecular basis and novel genetic targets for improved resistance to multiple fermentation inhibitors in Saccharomyces cerevisiae. Biotechnol Biofuels. 2016;9:9.

60. He M, Wu B, Shui Z, Hu Q, Wang W, Tan F, et al. Transcriptome profiling of Zymomonas mobilis under furfural stress. Appl Microbiol Biotechnol. 2012;95:189-99.

61. Hao X-C, Yang X-S, Wan P, Tian S. Comparative proteomic analysis of a new adaptive Pichia stipitis strain to furfural, a lignocellulosic inhibitory compound. Biotechnol Biofuels. 2013;6:34.

62. Guo W, Jia W, Li Y, Chen S. Performances of Lactobacillus brevis for producing lactic acid from hydrolysate of lignocellulosics. Appl Biochem Biotechnol. 2010;161:124-36.

63. Znameroski EA, Glass NL. Using a model filamentous fungus to unravel mechanisms of lignocellulose deconstruction. Biotechnol Biofuels. 2013;6:6.

64. Modig T, Liden G, Taherzadeh MJ. Inhibition effects of furfural on alcohol dehydrogenase, aldehyde dehydrogenase and pyruvate dehydrogenase. Biochem J. 2002;363:769-76.

65. Ziv C, Feldman D, Aharoni-Kats L, Chen S, Liu Y, Yarden O. The N-terminal region of the Neurospora NDR kinase COT1 regulates morphology via its interactions with MOB2A/B. Mol Microbiol. 2013:90:383-99.
66. Lopez-Moya F, Kowbel D, Nueda MJ, Palma-Guerrero J, Glass NL, LopezLlorca LV. Neurospora crassa transcriptomics reveals oxidative stress and plasma membrane homeostasis biology genes as key targets in response to chitosan. Mol BioSyst. 2016;12:391-403.

67. Trapnell C, Pachter L, Salzberg SL. TopHat: discovering splice junctions with RNA-Seq. Bioinformatics. 2009;25:1105-11.

68. Trapnell C, Williams BA, Pertea G, Mortazavi A, Kwan G, van Baren MJ, et al. Transcript assembly and quantification by RNA-Seq reveals unannotated transcripts and isoform switching during cell differentiation. Nat Biotechnol. 2010;28:511-5

69. de Hoon MJL, Imoto S, Nolan J, Miyano S. Open source clustering software. Bioinformatics. 2004;20:1453-4.

70. Conesa A, Götz S. Blast2GO: a comprehensive suite for functional analysis in plant genomics. Int J Plant Genom. 2008;2008:619832.

71. Herold I, Yarden O. Regulation of Neurospora crassa cell wall remodeling via the cot-1 pathway is mediated by gul-1. Curr Genet. 2017:63:145-59.

72. Freitag M, Hickey PC, Raju NB, Selker EU, Read ND. GFP as a tool to analyze the organization, dynamics and function of nuclei and microtubules in Neurospora crassa. Fungal Genet Biol. 2004;10:897-910.

73. Ziv C, Yarden O. Gene silencing for functional analysis: assessing RNAi as a tool for manipulation of gene expression. Methods Mol Biol. 2010;638:77-100.

74. Yarden O, Yanofsky C. Chitin synthase 1 plays a major role in cell wall biogenesis in Neurospora crassa. Genes Dev. 1991;5:2420-30.

75. Blecher-Gonen R, Barnett-Itzhaki Z, Jaitin D, Amann-Zalcenstein D, Lara-Astiaso D, Amit I. High-throughput chromatin immunoprecipitation for genome-wide mapping of in vivo protein-DNA interactions and epigenomic states. Nat Protoc. 2013;8:539-54.

76. Stajich JE, Harris T, Brunk BP, Brestelli J, Fischer S, Harb OS, et al. FungiDB: an integrated functional genomics database for fungi. Nucleic Acids Res. 2012;40:D675-81.

77. Chiang C, Layer RM, Faust GG, Lindberg MR, Rose DB, Garrison EP, et al. SpeedSeq: ultra-fast personal genome analysis and interpretation. Nat Methods. 2015;12:966-8.

78. Li H, Durbin R. Fast and accurate long-read alignment with BurrowsWheeler transform. Bioinformatics. 2010;26:589-95.

79. Faust GG, Hall IM. SAMBLASTER: fast duplicate marking and structural variant read extraction. Bioinformatics. 2014:30:2503-5.

80. Layer RM, Chiang C, Quinlan AR, Hall IM. LUMPY: a probabilistic framework for structural variant discovery. Genome Biol. 2014;15:R84.

81. Rizk G, Gouin A, Chikhi R, Lemaitre C. MindTheGap: integrated detection and assembly of short and long insertions. Bioinformatics. 2014;30:3451-7.

82. Anders S, Huber W. Differential expression analysis for sequence count data. Genome Biol. 2010;11:R106.

\section{Publisher's Note}

Springer Nature remains neutral with regard to jurisdictional claims in published maps and institutional affiliations.

Ready to submit your research? Choose BMC and benefit from

- fast, convenient online submission

- thorough peer review by experienced researchers in your field

- rapid publication on acceptance

- support for research data, including large and complex data types

- gold Open Access which fosters wider collaboration and increased citations

- maximum visibility for your research: over 100M website views per year

At BMC, research is always in progress.

Learn more biomedcentral.com/submissions 